\title{
Cryptorchidism in Sheep: A Clinical and Abattoir Survey in the United Kingdom
}

\author{
Keith C. Smith ${ }^{1}$, Peter J. Brown ${ }^{1,2}$, Frances J. Barr ${ }^{1}$, Tim J. Parkinson ${ }^{1,3}$ \\ ${ }^{1}$ School of Veterinary Science, University of Bristol, Bristol, UK \\ ${ }^{2}$ School of Veterinary Medicine and Science, University of Nottingham, Nottingham, UK \\ ${ }^{3}$ Institute of Veterinary, Animal and Biomedical Sciences, Massey University, Palmerston North, New Zealand \\ Email: peter.brown@nottingham.ac.uk
}

Received August 29, 2012; revised October 5, 2012; accepted November 5, 2012

\begin{abstract}
This paper describes features of a study of different aspects of cryptorchidism in sheep in different parts of England. A total of 83 crytorchid testes (57 unilateral and 13 bilateral) were recognised in 70 animals post-slaughter at three abattoirs in the south west of England between June 2000-January 2004. Abdominal cryptorchids (60) were common than inguinal (23); 69\% percent of cases were unilateral. External examination for cryptorchidism was carried out on 5134 young male lambs carried out in 2001 at Foot and Mouth Disease disposal sites, and on farms, during the UK outbreak of the disease. A total of 29 cases of cryptorchism [0.56\%] were detected; $86 \%$ of cases were unilateral. In both situations the right testis was more commonly affected than the left.
\end{abstract}

Keywords: Sheep; Cryptorchid; Abattoir; Survey

\section{Introduction}

A list, published in 1975 [1], of congenital defects of the male ovine reproductive system included cryptorchidism, testicular hypoplasia, perineal hypospadias and partial duplication of the male urogenital system. These were also the commonest congenital defects seen in 4417 lambs necropsied over three years [2] and in an abattoir survey of the reproductive tract of male sheep in the South West of England [3]. Features of a particularly high incidence of crytorchidism in North Ronaldsay sheep have recently been reported [4]. Cryptorchidism is also among the more common congenital abnormalities reported in surveys of reproductive tract abnormalities in sheep from overseas countries, mainly Australia [5-7]. Few of these overseas surveys have differentiated between animals of different ages, from lambs to rams. The culling of animals during the Foot and Mouth Disease in the UK between 2001 and 2002 provided an opportunity to examine a large number of male sheep, of known different age groups for clinical evidence of cryptorchidism. That study was supported by an abattoir investigation in which anatomical features of cryptorchid testes, and sites of retention, were able to be examined and recorded in detail for the first time.

\section{Materials and Methods}

\subsection{Abattoir Study}

The study took place at three slaughterhouses in the south west of England during the period June 2000 until January 31 st 2004 [within this interval there was a break during the outbreak of Foot and Mouth disease]. Animals killed included some reared in the West Country as well as others purchased by dealers from as far away as Scotland. Sheep were of typical lowland breeds, such as Texel crosses and Suffolk crosses. The slaughterhouses had line speeds that allowed the examinations indicated below to be carried out. With the exception of 70 young described below, animals were recorded as either ram lambs [prepubescent], hoggets [aged from their first autumn after birth until first shorn] or adult rams [mature rams that had been exposed to ewes].

Immediately after stunning and exsanguination, the scrotal area of each animal was checked prior to skinning. Entire ram lambs, in which both testes were present in the scrotum, and those with castration scars, were not examined further. Other lambs, in which one or both testes were absent, were marked and further examined at the point of evisceration. The anatomical site of the testes was recorded as 1) high abdominal; 2) mid abdominal; 3) low abdominal; or 4) inguinal and were photographed in situ. The testes and epididymides were then removed from the carcass and examined further. They were weighed, measured and their shape recorded; any abnormalities of distribution and apposition of the epididymis to the testis were also noted. Representative specimens were placed in formal saline for later histological examination. These were processed by routine 
paraffin wax embedding and sectioning, and were stained with haematoxylin and eosin. An additional 70 cases had been identified and retained for examination, by abattoir staff, in animals slaughtered in the absence of the main participant in the study (KCS). The ages of the 70 animals were not recorded; the total numbers of animals being slaughtered during such periods was also not recorded and it is not possible to calculate an incidence figure.

\subsection{Foot and Mouth Disease Examinations}

5134 young ( 2 to 4 months of age), uncastrated animals were available from groups of non-infected animals, of hill breeds, that were being euthanased by lethal intracardiac injection, as part of the foot-and-mouth disease control measures in the UK during 2001. While confirming successful euthanasia, the scrotum of lambs was examined for the presence of testes and any other abnormality. Sheep were of typical regional Hill breeds, such as Swaledales.

\section{Results}

Details of the cryptorchid animals detected in the abattoir survey, and in the Foot and Mouth Disease study, are described below. Further information of sizes, weights and distribution of cryptorchid testes from the abattoir study is also presented elsewhere [8].

\subsection{Abattoir Study}

During one part of the abattoir survey, 6521 lambs and hoggets and 786 adult rams (total 7307 animals) were examined during the slaughter house visits. Details of all the congenital abnormalities detected in the animals are presented elsewhere [3]. Cryptorchidism was detected in 70 animals (65 ram lambs and hoggets and five adult rams); 57 cases were unilateral and 13 bilateral, giving a total of 83 cryptorchid testes. Several of the cases had been identified, and retained for examination, by abattoir staff, in animals slaughtered in the absence of the main participant in the study (KCS). The total of animals being slaughtered during such periods was not recorded and it is not possible to calculate an incidence figure. The results are summarised in Table 1.

The proportions of cryptorchid animals varied between batches of lambs. Many groups had no cryptorchid animals, whereas the highest prevalence (2.4\%) was three unilateral cryptorchids in a single batch of 126 male Suffolk-type lambs being slaughtered. Five cryptorchid animals were detected in a total of 768 adult rams over the period of the survey, representing an incidence of $0.64 \%$. Unilateral cryptorchidism, both abdominal and inguinal, was more common than bilateral cryptorchidism. With a single exception, in bilateral cases both testes were found in the same position within the abdomen (high abdominal, mid abdominal or low abdominal) or in an inguinal position. The right testis was more often affected than the left; the site was not always recorded but amongst 29 ram lambs examined during the Foot and Mouth disease outbreak the right testis was affected in 18 cases and the left in 7 cases (four cases were bilateral).

The sizes and shapes of cryptorchid testes varied somewhat but were smaller, in size and weight, than normal testes (Figure 1). Abdominal testes were generally smaller than those present in the scrotum, and almost invariably of globoid or spheroidal shape; inguinal testes were generally rather more elongated.

Most epididymides associated with cryptorchid testes had an abnormal appearance; a range of similar changes were present in testes from all abnormal sites. Epididymal abnormalities included loss of testicular attachment, and even complete separation, of parts of the epididymis from the testis. With reduction in testicular size, epididymides appeared relatively enlarged; in extreme cases the testis was so small ("microtestes") that they were obscured by the epididymis and difficult to identify without histological confirmation of the presence of testicular tissue.

Table 1. Distribution of unilateral or bilateral cryptorchidism, at different sites, in rams.

\begin{tabular}{|c|c|c|c|c|}
\hline \multirow[t]{2}{*}{ Study } & \multirow[t]{2}{*}{ Site } & \multicolumn{2}{|c|}{ Distribution } & \multirow[t]{2}{*}{ Total } \\
\hline & & Unilateral & Bilateral & \\
\hline & $\begin{array}{c}\text { High } \\
\text { abdominal }\end{array}$ & 0 & 10 & 10 \\
\hline & $\begin{array}{c}\text { Mid } \\
\text { abdominal }\end{array}$ & 28 & $5^{\#}$ & 33 \\
\hline $\begin{array}{l}\text { Abattoir } \\
\text { survey }\end{array}$ & $\begin{array}{c}\text { Low } \\
\text { abdominal }\end{array}$ & 11 & 6 & 17 \\
\hline \multirow[t]{3}{*}{$\begin{array}{c}(7377 \\
\text { animals })\end{array}$} & $\begin{array}{c}\text { Total } \\
\text { abdominal } \\
\text { cryptorchids }\end{array}$ & 39 & 21 & 60 \\
\hline & $\begin{array}{l}\text { Total inguinal } \\
\text { cryptorchids }\end{array}$ & $18^{\#}$ & 5 & 23 \\
\hline & $\begin{array}{c}\text { Total } \\
\text { cryptorchids } \\
\text { in abattoir } \\
\text { survey }\end{array}$ & $\begin{array}{c}57[69 \%] \\
(0.75 \%)\end{array}$ & $\begin{array}{c}(26) 13^{\theta} \\
{[31 \%]} \\
(0.18 \%)\end{array}$ & $\begin{array}{c}70 \\
{[100 \%]} \\
(0.95 \%)\end{array}$ \\
\hline $\begin{array}{l}\text { FMD Cull } \\
\quad(5134 \\
\text { animals })\end{array}$ & Not known & $\begin{array}{c}25[86 \%] \\
(0.48 \%)\end{array}$ & $\begin{array}{c}(4) 2 \\
(14 \%] \\
(0.03 \%)\end{array}$ & $\begin{array}{c}27 \\
{[100 \%]} \\
(0.53 \%)\end{array}$ \\
\hline \multicolumn{2}{|c|}{$\begin{array}{c}\text { Overall combined } \\
\text { cryptorchids } \\
\text { (all sites) }(12,511 \text { animals })\end{array}$} & $\begin{array}{c}82[73 \%] \\
(0.65 \%)\end{array}$ & $\begin{array}{c}15 \\
{[27 \%]}\end{array}$ & $\begin{array}{c}97 \\
{[100 \%]}\end{array}$ \\
\hline
\end{tabular}

*7377 Animals identified and examined by KCS (3716 ram lambs, 2805 hoggets, 786 adult rams) and 70 animals retained by abattoir staff for further examination, whose ages were not recorded. "One mid abdominal, one inguinal, ${ }^{\theta} 26$ Bilateral cryptorchid testes (representing 13 animals); ${ }^{\square}$ bilateral cryptorchid testes (representing 2 animals). 


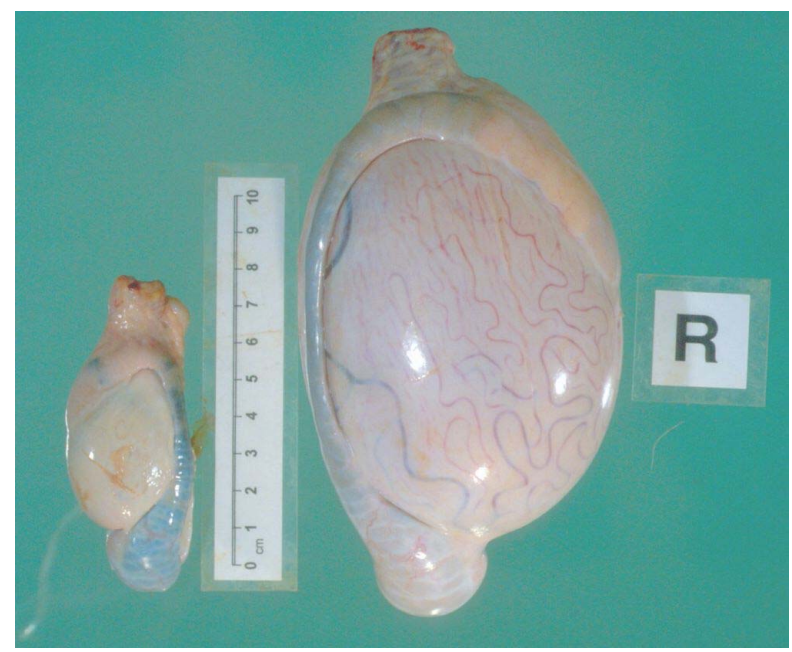

Figure 1. Normal right testis (R) and cryptorchid left testis, located at the entrance of the internal inguinal ring, from an adult ram. The cryptorchid testis is small and relatively elongated, the body of the epididymis is shortened; slight melanin pigmentation of the epididymis is an incidental finding.

\subsection{Foot and Mouth Disease Examinations}

A total of 5134 ram lambs were examined during the culling exercise associated with the Foot and Mouth Disease outbreak in the UK in 2001. Cryptorchidism was detected in a total of 29 animals, representing a prevalence of $0.56 \%$; the majority of cases (25 animals) were unilateral and the right testis (18 animals) was affected more often than the left (7 animals).

Histological examination of cryptorchid testes from abattoir specimens revealed the presence of hypoplastic seminiferous tubules; spermatogonia and Sertoli cells were present but there were no spermatocytes or postmeiotic cells; interstitial tissue was relatively normal but appeared relatively increased between small tubules (Figure 2).

\section{Discussion}

In a survey of 7307 rams [3], a total of 165 congenital lesions of the reproductive tract of male sheep were detected, alone or in combination, in 156 animals. That report included five cases of cryptorchidism in adult rams; cryptorchidism detected in younger rams in that survey are included in the current report. A roughly similar incidence of cryptorchidism has been described in some previous reports $(0.5 \%$ [9] and $0.6 \%$ [10]) from studies in the UK and USA respectively. The true incidence of cryptorchidism in male sheep in national flocks, in the UK and elsewhere, may not reflect these findings since all surveys are likely to have been biased in various ways, as a result of sources of animals and criteria for inclusion in their studies. They may be

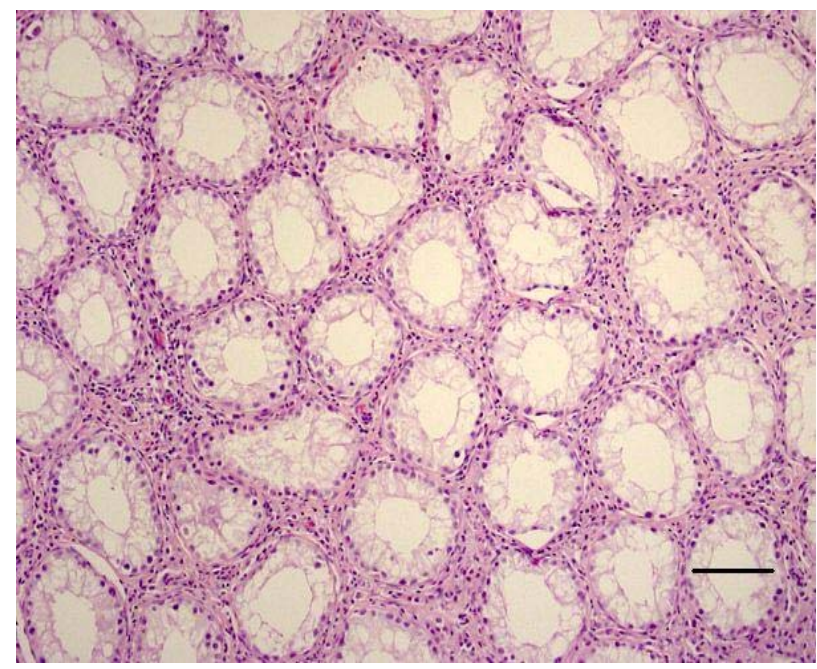

Figure 2. Typical microscopic appearance of crytorchid testis. Seminiferous tubules are small and there is no spermatogenic activity; interstitial Leydig cells are normal but appear relatively increased. Haematoxylin and Eosin Bar = $0.1 \mathrm{~mm}$.

affected by regional differences of common breeds and between animals reared for fattening or breeding purposes; some of the adult rams are likely to have been culled, possibly for infertility. The proportions of animals affected by cryptorchidism in the different parts of the study reported here varied $(70 / 7377[0.95 \%]$ in the abattoir survey and 29/5134 [0.56\%] in Foot and Mouth Disease cull animals).

The relatively higher incidence in the abattoir study reflects selection of the survey population by cooperative abattoir staff who detained carcases for further investigation of the site of retention of the testes. Also, a large proportion of hill lambs, examined during the Foot and Mouth Disease cull, will not have been castrated, reflecting normal management practice. A much higher incidence of cryptorchidism has been reported in ram lambs of the North Ronaldsay breed [4]; the recorded incidence in those animals ranged between $2.4 \%$ to 18.0\% (mean 7.4\%) between 1998 and 2003. In that study, and in all the groups of animals described here as well as other reports, [11,12] cryptorchidism is most commonly unilateral and affects the right testis.

The occurrence of epididymal abnormalities in association with cryptorchid testes has not been described previously in detail in sheep or most other domestic animals; one exception being dogs [13] in which epididymal detachment has been reported in some cases.

The investigation of cryptorchidism in UK sheep reported here suggests a prevalence of cryptorchidism of about just under $0.6 \%$; although it occurs at a low frequency, it cannot be considered a rare condition among the large number of sheep in the national flock. It has been suggested that unilateral cryptorchidism and tes- 
ticular hypoplasia might have the same hereditary basis $[14,15]$; the condition might be determined either by an autosomal recessive gene or by an autosomal dominant gene with incomplete penetrance [1]. The detection of cryptorchid animals amongst mature rams highlights the importance of proper clinical examination of rams prior to use as breeding sires.

\section{REFERENCES}

[1] G. Saperstein, H. W. Leipold and S. M. W. Dennis, "Congenital Defects of Sheep," Journal of the American Veterinary Medical Association, Vol. 167, No. 4, 1975, pp. 314-322.

[2] S. M. Dennis and H. W. Leipold, "Congenital Hernia in Sheep," Journal of the American Veterinary Medical Association, Vol. 152, No. 7, 1968, pp. 999-1003.

[3] K. C. Smith, P. J. Brown, F. J. Barr and T. J. Parkinson, "A Survey of Congenital Reproductive Abnormalities in Rams in Abattoirs in South West England," Reproduction in Domestic Animals, Vol. 47, No. 5, 2012, pp. 740-745. doi:10.1111/j.1439-0531.2011.01952.x

[4] K. C. Smith, P. J. Brown, J. Morris and T. J. Parkinson, "Cryptorchidism in North Ronaldsay Sheep," Veterinary Record, Vol. 161, No. 19, 2007, pp. 658-659. doi:10.1136/vr.161.19.658

[5] R. M. C. Gunn, "Studies in Sheep Fertility," Commonwealth of Australia Bulletin, Vol. 148, 1942.

[6] G. R. Moule, "Ovine Reproduction in Tropical Australia,” Australian Veterinary Journal, Vol. 42, No. 1, 1966, pp. 13-28. doi:10.1111/j.1751-0813.1966.tb04605.x

[7] D. A. Watt, "Testicular Pathology of Merino Rams," Australian Veterinary Journal, Vol. 54, No. 10, 1978, pp. 473-478. doi:10.1111/j.1751-0813.1978.tb00291.x

[8] K. C. Smith, "An Abattoir Study Involving The Examination of the External Genitalia of Rams," M.Sc. Thesis, University of Bristol, Bristol, 2006.

[9] A. Greig, "Ram Infertility," In: W. B. Martin and I. D. Aitken, Eds., Diseases of Sheep, 3rd Edition, Blackwell Scientific Publications, Oxford, 2000, pp. 65-70.

[10] R. Jensen and B. L. Swift, In: C. V. Kimberling, Ed., Diseases of Sheep, 3rd Edition, Lea and Febiger, Philadelphia, 1988, pp. 3-23.

[11] C. H. Dolling and M. G. Brooker, "Cryptorchidism in Australian Merino Sheep," Nature, Vol. 203, 1964, pp. 49-50. doi:10.1038/203049a0

[12] M. W. Bishop, "Genetically Determined Abnormalities of the Reproductive System," Journal of Reproduction and Fertility, Suppl. 15, 1972, pp. 51-78.

[13] V. S. Cox, L. I. Wallace and C. R. Jessen, "An Anatomic and Genetic Study of Canine Cryptorchidism," Teratology, Vol. 18, No. 2, 1978, pp. 233-240. doi:10.1002/tera. 1420180208

[14] A. N. Bruere, "Some Clinical Aspects of Hypo-Orchidism (Small Testes) in the Ram," New Zealand Veterinary Journal, Vol. 18, No. 9, 1970, pp. 189-198. doi:10.1080/00480169.1970.33897

[15] J. H. Claxton and N. T. M. Yeates, "The Inheritance of Cryptorchidism in a Small Crossbred Flock of Sheep," Journal of Heredity, Vol. 63, No. 3, 1972, pp. 141-144. 